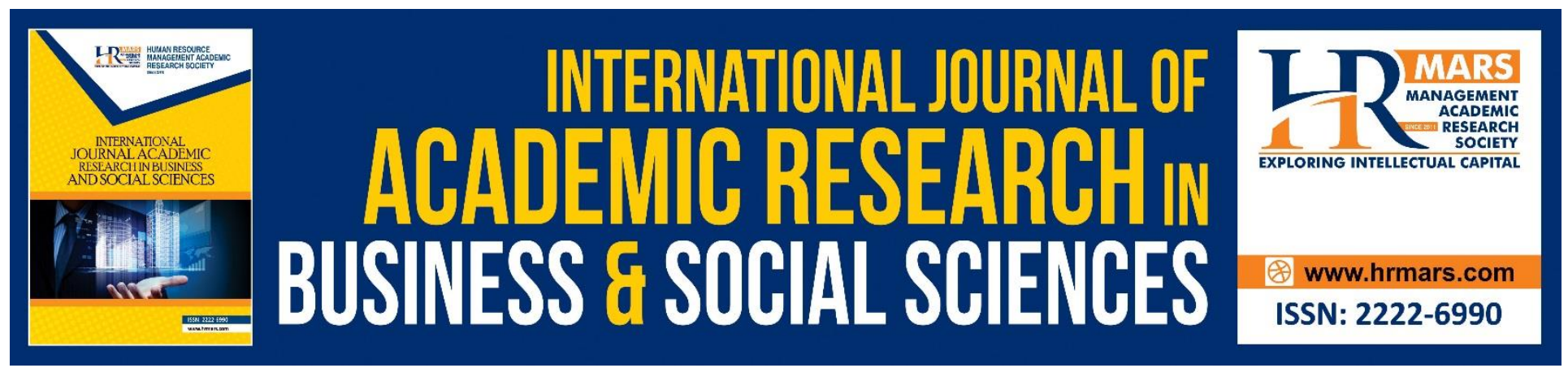

\title{
Moderation Effect of Impulsivity in The Relationship Between Depression and Suicide Ideation Among Late Adolescent in Malaysia
}

Mohd Radzi Tarmizi A Halim, Nor Ba'yah Abdul Kadir, Ab Rahman Roseliza Murni, Norhayati Ibrahim \& Muhamad Ariff Ibrahim

To Link this Article: http://dx.doi.org/10.6007/IJARBSS/v10-i10/7920 DOI:10.6007/IJARBSS/v10-i10/7920

Received: 10 July 2020, Revised: 19 August 2020, Accepted: 17 September 2020

Published Online: 09 October 2020

In-Text Citation: (Halim, et.al, 2020).

To Cite this Article: Halim, M. R. T. A., Abdul Kadir, N. B., Murni, Ab Rahman Roseliza., Ibrahim, N., \& Ibrahim, M. A. (2020). Moderation Effect of Impulsivity in The Relationship Between Depression and Suicide Ideation Among Late Adolescent in Malaysia. International Journal of Academic Research in Business and Social Sciences. 10(10), 110-119.

Copyright: () 2020 The Author(s)

Published by Human Resource Management Academic Research Society (www.hrmars.com)

This article is published under the Creative Commons Attribution (CC BY 4.0) license. Anyone may reproduce, distribute, translate and create derivative works of this article (for both commercial and non-commercial purposes), subject to full attribution to the original publication and authors. The full terms of this license may be seen at: http://creativecommons.org/licences/by/4.0/legalcode

Vol. 10, No. 10, 2020, Pg. $110-119$

Full Terms \& Conditions of access and use can be found at http://hrmars.com/index.php/pages/detail/publication-ethics 


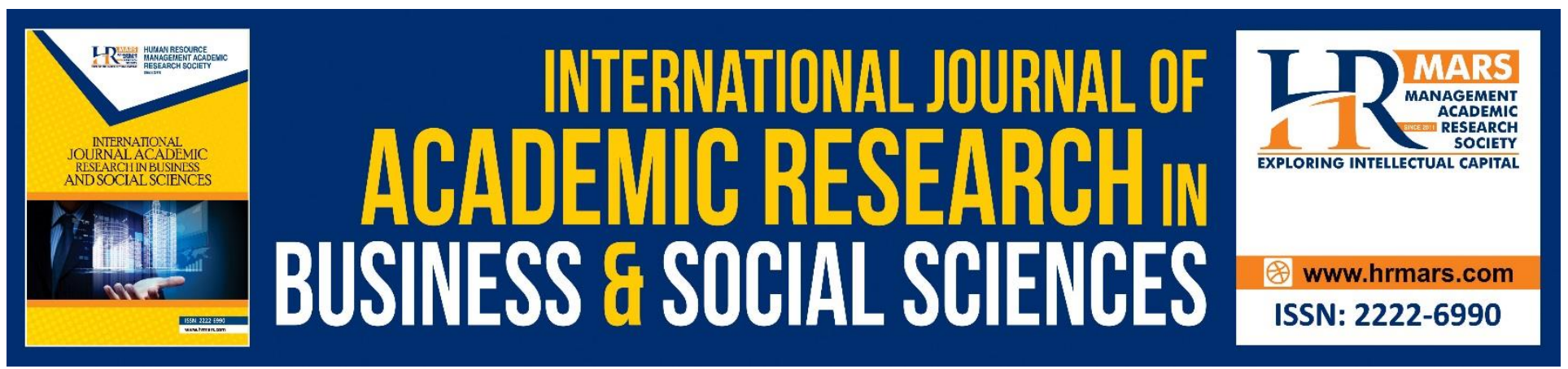

\title{
Moderation Effect of Impulsivity in The Relationship Between Depression and Suicide Ideation Among Late Adolescent in Malaysia
}

\author{
Mohd Radzi Tarmizi A Halim¹, Nor Ba'yah Abdul Kadir ${ }^{1}$, Ab Rahman \\ Roseliza Murni ${ }^{1}$, Norhayati Ibrahim² \& Muhamad Ariff Ibrahim ${ }^{3}$. \\ ${ }^{1}$ Psychology and Human Well-Being Research Centre, Faculty of Social Sciences and Humanities, \\ Universiti Kebangsaan Malaysia, Bangi, Selangor, ${ }^{2}$ Health Psychology Programme, Faculty of Health \\ Sciences, Universiti Kebangsaan Malaysia, Kuala Lumpur, ${ }^{3}$ Department of Nutrition Sciences, \\ Kulliyyah Allied Health Sciences, International Islamic University Malaysia, Kuantan, Pahang
}

\begin{abstract}
Introduction: The increasing prevalence of suicidal behavior among adolescents in Malaysia recorded for the past decades needs further attention and investigation. Past research has suggested that impulsivity serves as a predictor and risk factor for suicidal ideation. The role of impulsivity as a moderator in the relationship between depression and suicidal ideation among late adolescents in Malaysia were understudied. Objectives: This study aims to identify the relationship between impulsivity, depression and suicide ideation and examine the moderation properties of impulsivity in depression and suicide ideation relationships among late adolescents in Malaysia. Methods: A crosssectional survey was conducted involving 577 respondents recruited among university students who were currently pursuing their study in public universities located in Wilayah Persekutuan Kuala Lumpur and Selangor. The Short Version UPPS-P Impulsive Behaviour Scale (SUPPS-P), Center for Epidemiologic Studies Depression Scale-Revised (CESD-R) and Revised Suicide Ideation Scale (R-SIS) was utilized to obtain the data regarding impulsivity personality trait, depression and suicide ideation respectively. Results and Discussion: Results show that impulsivity correlated positively and significantly with depression and suicide ideation. Impulsivity was also found to moderate the relationship between depression and suicidal ideations. Furthermore, the suicidal individual with high intention to die exhibit impulsivity traits equally to individuals with self-inflicted injury and has no intention to die. Conclusion: In summary, impulsivity personality trait shall be treated as a profound risk factor when combined with depressive symptoms in elevating the probability of suicide among late adolescents. Therefore, impulsivity trait screening should be practiced during the initial clinical interview, especially among high-risk groups.
\end{abstract}

Keywords: Impulsivity, Depression, Suicide Ideation, Adolescent, Malaysian 
INTERNATIONAL JOURNAL OF ACADEMIC RESEARCH IN BUSINESS AND SOCIAL SCIENCES Vol. 10, No. 10, 2020, E-ISSN: 2222-6990 @ 2020 HRMARS

\section{Introduction}

The historical data of Malaysia's suicide rate states a 5.10 suicide rate per 100000 population in 2010. However, in more recent years, the numbers jump into a 5.50 suicide rate per 100000 population (WHO, 2018). The rate is lower than other neighboring countries like Thailand (14.4 per 100000 population) World Health Organization (WHO) reported that the suicide incident is underreported, especially among religion-oriented countries, such as Malaysia (WHO, 2018). Therefore, the prevalence and suicide rate in Malaysia is questionable.

Suicide is the second leading cause of death among youngsters aged between 15 and 29 globally (WHO, 2019). For the past decades, the number of suicide behavior among Malaysian adolescents is increasing and alarming. Ahmad et al. (2014) reported that the youngest age with suicide behavior is 12 years old in Malaysia. National Health Morbidity Survey (NHMS) reported the increasing trend in all three types of suicide behavior from 2012 to 2017 among Malaysian adolescents. The prevalence of suicide ideation increased from $7.9 \%$ in 2012 to $10.0 \%$ in the year 2017. Plan and suicide attempt, increase from $6.8 \%$ to $7.3 \%$ and $6.4 \%$ to $6.9 \%$ respectively from the year 2012 to 2017 (Institute for Public Health, 2017).

Our experience in dealing with suicidal clients in the clinic shows that they have no further specific plan of suicide and become doubtful when acting to suicide. Most of them claim that suicide attempted to reduce negative emotions triggered by a particularly stressful event or trying to escape from certain situations with no strong reason to die. This suicide behavior contradicts with The Joiner's (2005) interpersonal theory of suicide which he proposes that people become highly suicidal when they have the capability to suicide, a firm intention to die, a strong feeling of burdensomeness and has a higher tolerance to pain due to prolonged engaging and painful experiences.

However, the person with an impulsive act of suicide lacks these criteria and acting on suicide just to relieve the stressful event with no plan or reason to suicide but aims to die. Compared to self-inflicted injury individuals, they also act on hurting themselves to reduce the negative emotional symptoms, but they have no intention to die. The element of impulsivity in these impulsive acts of suicide was understudied in Malaysia, compared to other risk factors such as gender, depression and other psychopathological and demographic profiles. To our knowledge, the research concerning impulsivity trait in suicide behavior in Malaysia, especially in adolescents, is limited, although the role of impulsivity as a risk factor of suicide was recognized in other countries (Auerbach et al., 2017; Lockwood et al., 2017). Therefore, our objectives of this study are to identify the relationship between impulsivity, depression and suicide ideation and to examine moderation properties of impulsivity in depression and suicide ideation relationships.

\section{Methods}

This current study is apart from a larger study conducted by the researcher with ethical approval from the Medical Research \& Ethics Committee (MREC), Ministry of Health Malaysia. A sample of 577 volunteered adolescents aged ranging from 18 to 24 years old was recruited using a stratified random sampling of the cross-sectional survey from several public universities in Wilayah Persekutuan Kuala Lumpur and Selangor. Following the ethical protocols, the respondents were given a briefing about the study's procedure and potential risk that may arise. The respondent who has signed the consent form to volunteer to be studied was handed up with a copy of the questionnaire contains the demographic item, The Short Version UPPS-P Impulsive Behaviour Scale (SUPPS-P), Center for Epidemiologic Studies Depression Scale-Revised (CESD-R) and Revised Suicide Ideation Scale (R-SIS). 
INTERNATIONAL JOURNAL OF ACADEMIC RESEARCH IN BUSINESS AND SOCIAL SCIENCES Vol. 10, No. 10, 2020, E-ISSN: 2222-6990 @ 2020 HRMARS

The completed questionnaire is stored in the researcher's office in a secured and locked cabinet to ensure its safety. The data were analyzed using the Statistical Package for Social Science version 24.0. The analysis involved the descriptive statistics analysis, Pearson correlation analysis and PROCESS MACRO for SPSS in calculating the moderation model. The PROCESS MACRO is an additional function installed in the SPSS to calculate multivariate analysis introduced by Hayes (2018). Over the thorough literature review, we found the inconsistency between impulsivity and depression towards suicidal ideation. Baron and Kenny (1986) suggested introducing the moderating variable when there is unexpectedly weak or inconsistent relation between the independent and dependent variables. So, we introduced impulsivity as a moderator in the relationship between depression and suicide ideation.

\section{Instruments}

\section{Short Version UPPS-P Impulsive Behaviour Scale (SUPPS-P)}

This scale was developed by Whiteside and Lynam (2001) and contained 20 items measuring five subscales of impulsivity, namely Negative Urgency, Lack of Perseverance, Lack of Premeditation, Sensation Seeking and Positive Urgency. Positive Urgency is an addition to the original subscale of impulsivity, and it was proposed and developed by Smith et al. (2007). Cyders, Littlefield, Coffey and Karyadi (2014) examined the statistical properties of this scale and reported a good internal consistency with Cronbach alpha, $\alpha$ ranging from .74 - .85. Negative Urgency, lack of premeditation, and sensation seeking also found correlated positively and significantly with self-inflicted injury among the sample they studied. The cut-off score to define high impulsivity is $\mathbf{5 0}$ and above is used for this study.

\section{Center for Epidemiologic Studies Depression Scale-Revised (CESD-R)}

Radloff (1977) originally developed this scale, which contains 20 items that measure depressive symptoms. Later on, Eaton et al. (2004) revised this scale to ensure it can measure the depressive symptoms as defined in the Diagnostic and Statistical Manual of Mental Disorders (DSM) published by the American Psychiatric Association. Nine depressive symptoms could be measured, namely Sadness (Dysphoria), Loss of interest (Anhedonia), Appetite, Sleep, Thinking/Concentration, Guilt (Worthlessness), Tired (Fatigue), Movement (Agitation) and Suicidal Ideation. The reliability test in terms of internal consistency yielded high Cronbach alpha, $\alpha$, which range from $.85-.90$ (Radloff, 1977; Hunter et al., 2003). The Malay version of this scale also shows good internal consistency, $\alpha=$ .78 and correlated well with Hospital Anxiety and Depression Scale Malay version (HADS) and the original version of CESD (Ahmad Sabki, Zainal \& Guan, 2014). According to Eaton et al. (2004), individuals who scored 16 and above have a significant subthreshold of depressive symptoms.

\section{Revised Suicide Ideation Scale (R-SIS)}

The suicide ideation was measured using the Revised Suicide Ideation Scale (R-SIS) developed by Rudd (1989). Rudd (1989) claims that these scale items represent a continuum of suicidal ideation that started from suicidal thoughts to more intense ideation and actual suicide attempts. This continuum meant to be measured using ten items that dispersed into two dimensions, including suicidal behavior and suicide feel. In terms of statistical properties, Rudd (1989) reported R-SIS correlated well with the Center for Epidemiologic Studies Depression (CESD) with $r=.55, p<0.001$, and has an excellent internal consistency with Cronbach alpha, $\alpha=.91$. Besides, the cut-off score to 
INTERNATIONAL JOURNAL OF ACADEMIC RESEARCH IN BUSINESS AND SOCIAL SCIENCES

Vol. 10, No. 10, 2020, E-ISSN: 2222-6990 @ 2020 HRMARS

detect the high risk of potential suicide behavior in individuals is 15 and above (Rudd, 1989; Luxton et al., 2011).

\section{Results}

\section{Demographic Profile}

A sample of 577 adolescents was examined and gathered their demographic profile. Table 1 shows the majority of the respondent is female (70.5\%), Malay (66.6\%) and Muslims (69.3\%) with the highest education level started from a certificate from a matriculation college. Most of them come from low-income families, which earns below RM 3860 per month (57.5\%). Another demographic component also examines the mental health issues that existed within the family of the respondents. About $7.6 \%$ of the sample reported that their family members suffered from various mental health issues. Other $10.2 \%$ reported that they have family members or friend who has an episode of attempted and completed suicide. Specifically, most of them witnessed friends involved in suicide behavior (5.9\%), while other $2.7 \%$ experienced with family members attempted or committed suicide. The prevalence of impulsivity, depression and suicide ideation based on its cut-off score in this study is $19.93 \%, 44.02 \%$ and $18.37 \%$, respectively.

Table 1: Respondent's demographic profiles

\begin{tabular}{|c|c|c|c|}
\hline \multicolumn{2}{|r|}{ Demographic Component } & \multirow[t]{2}{*}{ Frequency } & \multirow[t]{2}{*}{ Percentage } \\
\hline Gende & & & \\
\hline i) & Male & 170 & 29.5 \\
\hline ii) & Female & 407 & 70.5 \\
\hline \multicolumn{4}{|l|}{ Race } \\
\hline i) & Malay & 384 & 66.6 \\
\hline ii) & Chinese & 134 & 23.2 \\
\hline iii) & Indian & 40 & 6.9 \\
\hline iv) & Bumiputera of Sabah \& Sarawak & 16 & 2.8 \\
\hline v) & Indigenous People & 1 & 0.2 \\
\hline vi) & Others & 2 & 0.3 \\
\hline \multicolumn{4}{|c|}{ Religion } \\
\hline i) & Islam & 400 & 69.3 \\
\hline ii) & Hinduism & 40 & 6.9 \\
\hline iii) & Buddhism & 129 & 22.4 \\
\hline iv) & Christian & 5 & 0.9 \\
\hline v) & Atheist & 2 & 0.3 \\
\hline vi) & Others & 1 & 0.2 \\
\hline \multicolumn{4}{|c|}{ Highest Education Level } \\
\hline i) & Matriculation College & 118 & 20.5 \\
\hline ii) & Diploma & 107 & 18.5 \\
\hline iii) & Degree & 352 & 61.0 \\
\hline \multicolumn{4}{|c|}{ Family Gross Income } \\
\hline i) & 0: Low Income < RM 3860) & 332 & 57.5 \\
\hline
\end{tabular}


INTERNATIONAL JOURNAL OF ACADEMIC RESEARCH IN BUSINESS AND SOCIAL SCIENCES Vol. 10, No. 10, 2020, E-ISSN: 2222-6990 @ 2020 HRMARS

ii) M40: Medium Income RM 3860 - RM 8319)

204

35.4

iii) T20: High Income > RM8319)

Family Members with Mental Health Issue

$\begin{array}{llcc}\text { i) } \quad \text { Yes } & \text { No } & 44 & 7.6 \\ \text { ii) } & \text { No } & 533 & 92.4\end{array}$

Family Members or Friend Who Attempted and Completed Suicide
i) Yes
59
10.2
ii) No
518
89.8

\section{Relationship With The Suicidal Person}

i) Family Members $\quad 16 \quad 2.7$

ii) Friend $\quad 34 \quad 5.9$

iii) Family members and friend $\quad 1 \quad 0.2$

iv) Not stated $\quad 1 \quad 0.2$

v) Not applicable $\quad 525 \quad 91$

The Pearson correlation analysis was conducted to answer the first research objective. The impulsivity is found to significantly increase the depressive symptoms, where it both positively correlated with the Pearson correlation coefficient, $r=.321, p<.001$. Furthermore, as the impulsivity increase, the severity of suicide ideation also significantly increase where it both positively correlated with the Pearson correlation coefficient, $r=.248, p<.001$. On the other hand, as the depressive symptoms increase, the suicide ideation also significantly increases, where it both positively correlated with the Pearson correlation coefficient, $r=.642, p<.001$.

Table 2: Correlation coefficient between impulsivity, depression and suicide ideation

\begin{tabular}{lccc}
\hline & Impulsivity & Depression & Suicide Ideation \\
\hline Impulsivity & 1 & $.321^{* *}$ & $.248^{* *}$ \\
Depression & 1 & $.642^{* *}$ \\
Suicide Ideation & & 1 \\
\hline$* *$ Correlation is significant at the 0.01 level (2-tailed).
\end{tabular}

The moderation analysis using PROCESS Macro for SPSS by Hayes (2018) was executed to answer the second objective of this study. Table 3 shows that the moderation model contribute $43.46 \%$ of the variance change, $\mathrm{R} 2=.4346, \mathrm{p}<.001$. Furthermore, the analysis confirmed that depression and suicide ideation relationship were moderated by impulsivity and there is a significant interaction was occurred, $b=.0078,95 \% \mathrm{Cl}(.0045, .0112), \mathrm{t}=4.5926, \mathrm{p}<.001$. Besides, to illustrate the interaction, a simple slope graph is plotted, as in Figure 2. When the level of impulsivity is low $=37$, there are significant relationship between depression and suicide ideation, $b=.1749,95 \% \mathrm{Cl}(.1370, .2128), \mathrm{t}$ $=9.0568, p=.000$. When the level of impulsivity is equal to the mean $=43$, there are significant relationship between depression and suicide ideation $b=.2218,95 \% \mathrm{Cl}(.1954, .2483), t=16.4735, p$ $=.000$. Lastly, when the level of impulsivity is high $=51$, there are significant relationship between depression and suicide ideation, $b=.2844,95 \% \mathrm{Cl}(.2533, .3155), t=17.9606, p=.000$. Interestingly, all of the interactions yielded positive value, and it suggests that impulsivity does not change the relationship direction of depression and suicide ideation. As impulsivity increases, depression will increase, and no matter how low the level of impulsivity is, it still has interaction in the relationship 
INTERNATIONAL JOURNAL OF ACADEMIC RESEARCH IN BUSINESS AND SOCIAL SCIENCES Vol. 10, No. 10, 2020, E-ISSN: 2222-6990 @ 2020 HRMARS

between depression and suicide ideation. Therefore, when the level of impulsivity increased and combined with elevating depressive symptoms, the severity of suicide ideation increased.

Table 3: Moderation analysis

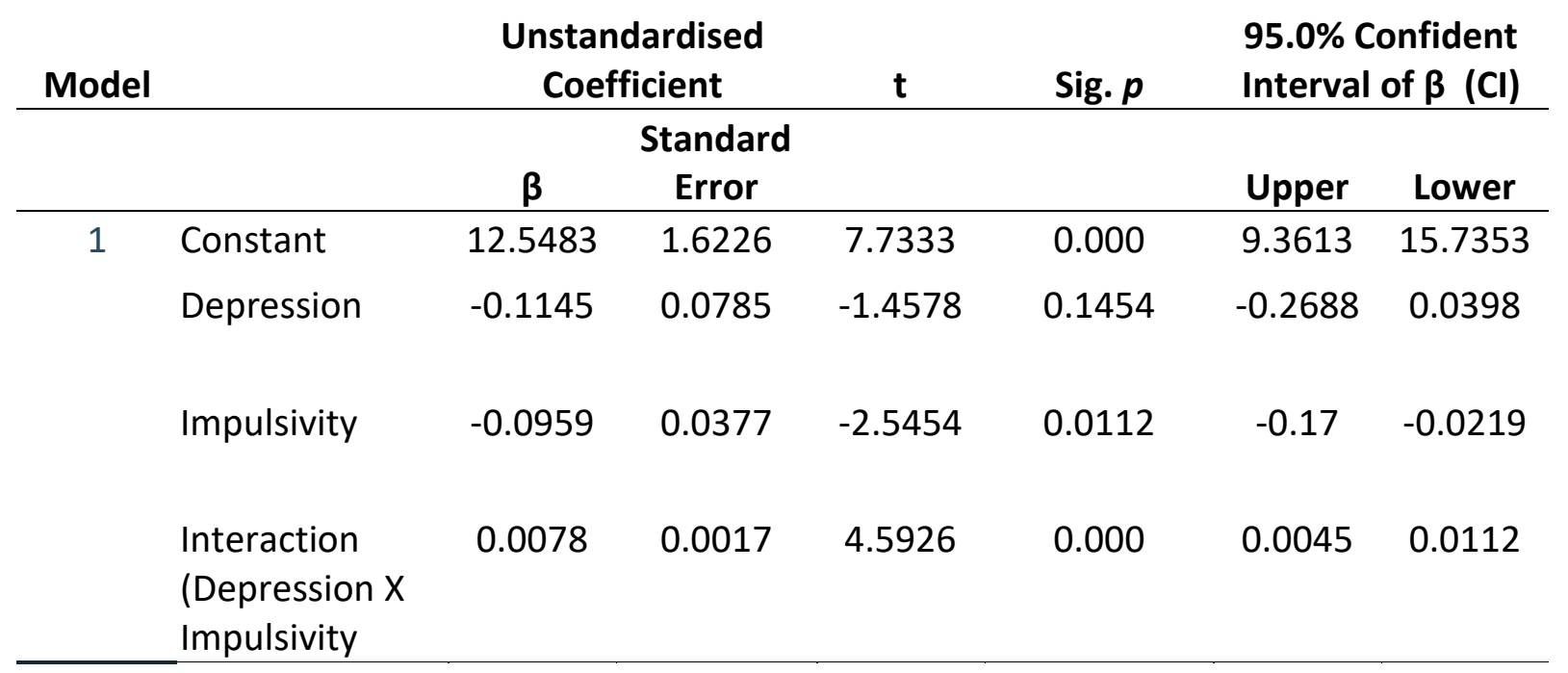

a. Dependent Variable: Suicide Ideation, $R^{2}=.4346, p<.001$

Figure 1: Simple slope of impulsivity analysis

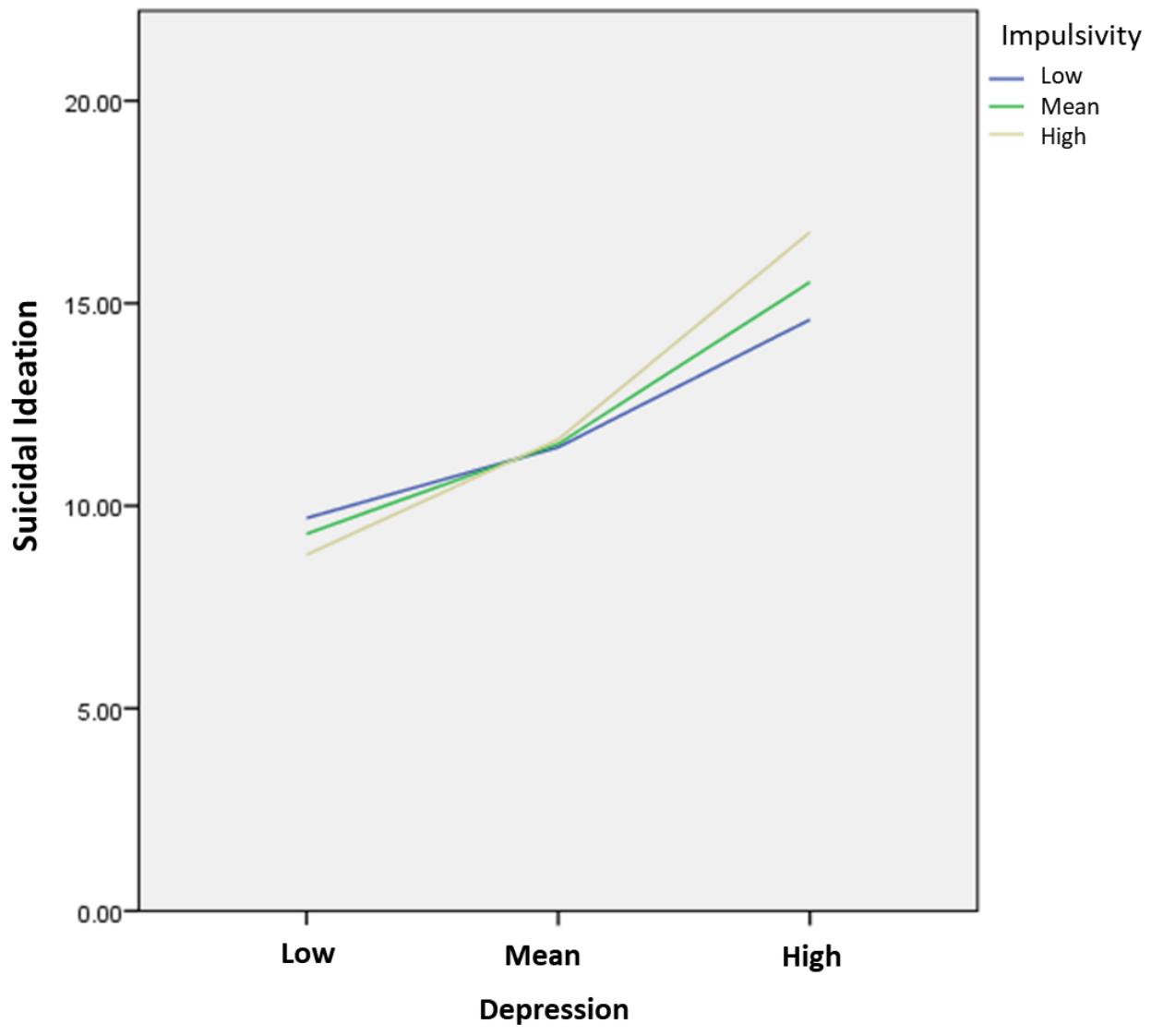


INTERNATIONAL JOURNAL OF ACADEMIC RESEARCH IN BUSINESS AND SOCIAL SCIENCES Vol. 10, No. 10, 2020, E-ISSN: 2222-6990 @ 2020 HRMARS

Figure 4: Conceptual model of impulsivity as a moderator in depression and suicide ideation relationship.

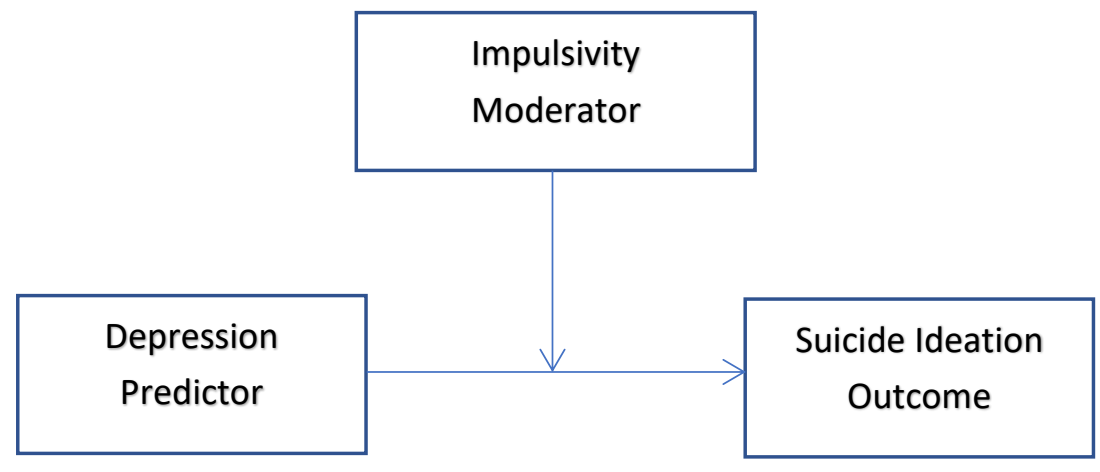

\section{Discussion}

The increment of suicidal behavior among adolescents in Malaysia needs further attention. This study found that adolescents raised in the family with psychological issues such as having a pre-existing mental illness and suicidal behavior may contribute to suicidal ideation. As suggested by several past research, Cerel and Robert (2005), for example, explained adolescent who had experienced a family member's death by suicide were more likely to have suicidal ideation and attempts, involved in marijuana and alcohol misuse, inflicting severe injuries and emotional distress. Other researchers such as Brent et al. (1992) found that siblings who had experienced suicide more likely to exhibit newonset depression. Therefore, the pre-existing suicidal behavior among family members may be served as a distal risk factor of suicidal behavior among adolescents in the future, and this issue needs more investigation and prevention.

The moderation analysis suggests impulsivity able to moderate the relationship between depression and suicide ideation among adolescents studied, consistent with findings acquired by da Silva et al. (2018) and Lockwood et al. (2017) in their studies. The simple slope analysis shows that all three impulsivity levels have significant interaction with the depression and suicide ideation relationship. This interpretation contrast with what Wang et al. (2015) found in their study, which only moderate to a high level of impulsivity has significant interaction to suicide ideation. Therefore, we argue that only a high level of impulsivity needs attention because current findings suggested that at the low level of impulsivity, it still has an effect on depression and further elevates risks to suicidal ideation. The abundance of past research either from local or abroad suggest that depression is a major risk factor to suicide (Norhayati et al., 2014; Aqeel Khan et al., 2014). Even the American Psychiatric Association (2013) listed suicide behavior as a major symptom in several psychopathological issues, especially depression. However, suicide behavior itself is not recognized as a diagnosis but rather than symptoms co-existed with other psychological issues. Meanwhile, Joiner (2005) believed that provocative and painful experiences repetitively make individuals feel less pain and less fear of death overtime. Such provocative and painful experiences or other stressors may develop into depression. However, such explanations tend to overlook the fact that impulsivity has a vital role in strengthening the act of suicide by way of the inability to regulate or rationale behavior during negative mood among depressed individuals. Thus it elevates the risk of suicide. Furthermore, no research has found that depression alone contributes more than $90 \%$ of the variance changes to suicide behavior. Nevertheless, in the current study, the model produces almost $50 \%$ of variance changes in suicide 
INTERNATIONAL JOURNAL OF ACADEMIC RESEARCH IN BUSINESS AND SOCIAL SCIENCES

Vol. 10, No. 10, 2020, E-ISSN: 2222-6990 @ 2020 HRMARS

ideation suggest that impulsivity increases depressive mood, which in turn elevate the suicide ideation.

\section{Conclusion}

In Malaysia, the Ministry of Health recommends DASS-21 as a screening tool to detect any symptoms of depression, anxiety or stress before a referral is made to the mental health professionals. Even though we found that impulsivity has a significant correlation and can moderate the relationship between depression and suicide ideation, further work is required to establish this. There is ample room for further progress in determining which of the subscales in impulsivity contribute to depression and suicidal behavior. Other than that, a longitudinal study needed to see how impulsivity developed until it reaches the moment it becomes a risk factor to suicide behavior, especially among drug and alcohol users, individuals with a history of mental health issues running in their family or even individuals with brain injury. A further analysis was comparing the level of impulsivity between self-inflicted injury and no intention to die also needed to study. Another, we suggested examining mental health issues and suicidal behavior among family members as a predictor of suicidal behavior among adolescents in the future.

\section{Acknowledgement}

We would like to thank all respondents who volunteered to participate in this study.

\section{Ethics approval and consent to participate}

This research has been reviewed and approved by the Medical Research \& Ethics Committee (MREC), Ministry of Health Malaysia, with approval number NMRR-17-2471-38272 (IIR). All procedure took place in this study which involved human sample is compiled following the ethical standards highlighted by MREC. Each respondent who participated in this study was briefed about the study procedure and volunteered to sign the consent form. There is no consent from a parental or legal guardian, as all of the respondents are above 18 years old.

\section{References}

Sabki, A. Z., Zainal, N. Z., \& Guan, N. C. (2014). Exploratory factorial analysis and reliability of the Malay version of centre for epidemiological studies - depression scale (MCES-D) in a group of Malaysian junior doctors. International Journal of Academic Research Part B, 6(2): 333-337.

Ahmad, N., Cheong, S. M., Ibrahim, N., \& Rosman, A. (2014). Suicidal ideation among Malaysian adolescents. Asia-Pacific journal of public health / Asia-Pacific Academic Consortium for Public Health, 26: 63S-9S.

American Psychiatric Association. (2013). DSM -5. American Psychiatric Association.

Auerbach, R. P., Stewart, J. G., \& Johnson, S. L. (2017). Impulsivity and suicidality in adolescent inpatients. J Abnorm Child Psychol, 45(1): 91-103.

Brent, D. A., Perper, J., Moritz, G., Allman, C., Friend, A., Schweers, J., Roth, C., Balach, L., \& Harrington, K. (1992). Psychiatric effects of exposure to suicide among the friends and acquaintances of adolescent suicide victims. Journal of the American Academy of Child and Adolescent Psychiatry, 31(4): 629-639.

Cerel, J., \& Roberts, T. A. (2005). Suicidal behavior in the family and adolescent risk behavior. Journal of Adolescent Health, 36: 352-16. 
INTERNATIONAL JOURNAL OF ACADEMIC RESEARCH IN BUSINESS AND SOCIAL SCIENCES

Vol. 10, No. 10, 2020, E-ISSN: 2222-6990 @ 2020 HRMARS

Da Silva, A. G., Malloy-Diniz, L. F., Garcia, M. S., Figueiredo, C. G. S., Figueiredo, R. N., Diaz, A. P., \& Palha, A. P. (2018). Cognition as a therapeutic target in the suicidal patient approach. Front. Psychiatry, 9(31): 1-5.

Eaton, W. W., Muntaner, C., Smith, C., Tien, A., \& Ybarra, M. (2004). Center for Epidemiologic Studies Depression Scale: Review and revision (CESD and CESDR). In M.E. Maruish (Ed.). The use of psychological testing for treatment planning and outcomes assessment, Volume 3: Instruments for adults ( $3^{\text {rd }}$ ed.). Edition. pp. 363-377). Hillsdale, NJ: Erlbaum Associates.

Hayes, A. F. (2018). Introduction to mediation, moderation, and conditional process analysis: $A$ regression-based approach ( $2^{\text {nd }}$ ed.). The Guildford Press. New York.

Hunter, W. M., Cox, C. E., Teagle, S., Johnson, R. M., Mathew, R., Knight, E. D., \& Leeb, R.T. (2003). Measures for Assessment of Functioning and Outcomes in Longitudinal Research on Child Abuse. Volume 1: Early Childhood. http://www.iprc.unc.edu/longscan/. [20 Julai 2014].

Institute for Public Health. (2017). The national health and mobidity survey 2017: Adolescent Mental Health (DASS-21). Minstry of Health Malaysia.

Joiner, T. (2005). Why people die by suicide. Cambridge, MA, US: Harvard University.

Lockwood, J., Daley, D., Townsend, E., \& Sayal, K. (2017). Impulsivity and self-harm in adolescence: a systematic review. Eur Child Adolesc Psychiatry, 26: 387-402.

Luxton, D. D., Rudd, M. D., Reger, M. A., \& Gahm, G. A. (2011). A Psychometric Study of the Suicide Ideation Scale. Archives of Suicide Research, 15(3): 250-258.

Radloff, L. S. (1977). The CES-D Scale: A self-report depression scale for research in the general population. Applied Psychological Measurement, 1(3): 385-401.

Rudd, M. D. (1989). The Prevalence of Suicidal Ideation among College Students. Suicide and LifeThreatening Behaviour, 19(2): 173-183.

Smith, G. T., Fischer, S., Cyders, M. A., Annus, A. M., Spillane, N. S., McCarthy, D. M. (2007). On the validity and utility of discriminating among impulsivity-like traits. Assessment, 14(2):155-170.

Wang, Y-Y., Jiang, N-Z., Cheung, E. F. C., Sun, H-W., \& Chan, R. C. K. (2015). Role of depression severity and impulsivity in the relationship between hopelessness and suicidal ideation in patients with major depressive disorder. Journal of Affective Disorder, 183(2015), 83-89.

Whiteside, S. P., \& Lynam, D. R. (2001). The Five Factor Model and impulsivity: Using a structural model of personality to understand impulsivity. Personality and Individual Differences, 30(4): $669-689$.

World Health Organization (WHO). (2018). Suicide mortality rate. Geneva: World Health Organization.

World Health Organization (WHO). (2019). Suicide: One person dies every 40 seconds. Geneva: World Health Organization. 